\title{
Complementary health approach to quality of life in menopausal women: a community-based interventional study
}

This article was published in the following Dove Press journal:

Clinical Interventions in Aging

7 November 2014

Number of times this article has been viewed

\section{Baskaran Jayabharathi Arulappan Judie \\ SRM College of Nursing, SRM University, Kattankulathur, \\ Kancheepuram District, \\ Tamil Nadu, India}

\section{Video abstract}

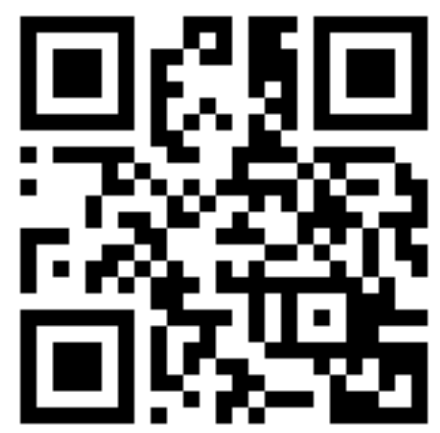

Point your SmartPhone at the code above. If you have a QR code reader the video abstract will appear. Or use:

http://dvpr.es/ItU0.9u

Correspondence: Baskaran Jayabharathi SRM College of Nursing, SRM University, Kattankulathur, Kancheepuram District, 603203, Tamil Nadu, India

Email jayabharathimariyappan23@gmail.com
Background: Menopause is the stage when the menstrual period permanently stops, and is a part of every woman's life. It usually occurs between the ages of 40 and 60 years, and is associated with hormonal, physical, and psychological changes. Estrogen and progesterone levels play the biggest part in menopause. In this stage, the ovaries make less estrogen and progesterone. When the body produces less of these hormones, the parts of the body that depend on estrogen to keep them healthy will react and this often causes discomfort for women. This study tested the impact of a complementary health approach to quality of life in menopausal women.

Methods: A community-based interventional study was conducted in selected areas in Kattankulathur Block, Kanchipuram District, Tamil Nadu, India. A simple random sampling technique was used to select menopausal women for the study. Of 260 menopausal women identified, 130 were allocated to a study group and 130 to a control group. The study group underwent yoga training for 1.5 hours per day on 5 consecutive days. After the 5 -day intensive yoga training program, the menopausal women practiced yoga daily at home for 35-40 minutes a day. Along with daily yoga practice, they underwent group yoga practice for 2 days a week under the supervision of one of the investigators until 18 weeks. The yoga training program consisted of Yogasanas, Pranayama (breathing exercises), and meditation. The standardized World Health Organization QoL BREF scale was used to assess the women's quality of life. We distributed an instruction manual on steps of selected yoga practice for the women's selfreference at home after the 5 days of continuous yoga practice. A yoga practice diary was used to confirm regular performance of yoga. The women in the control group did not participate in the yoga program; however, on completion of the study, these women received intensive yoga training for 5 days.

Results: There was an extremely high statistically significant difference $(P=0.001)$ between the study group and the control group with regard to the physical, psychological, social, and environmental domains of quality of life after 6,12 , and 18 weeks of yoga therapy. The mean gain score was high in all the domains of quality of life in the study group at weeks 6,12 , and 18. The overall mean gain score in the study group was 31.58 versus 1.61 in the control group. The overall mean gain score difference was 29.97 in all domains of quality of life between the study group and the control group. In the study group, the physical, psychological, social, and environmental domains of quality of life were greatly improved by practicing yoga for 18 weeks. No adverse events were reported by the women after yoga practice.

Conclusion: Quality of life in menopausal women was greatly improved after 18 weeks of yoga practice. Women who regularly practice yoga find that they are able to enjoy menopause and experience the freedom, liberation, and energy that it brings. We conclude that yoga is an effective complementary health approach for improving quality of life in menopausal women.

Keywords: complementary health approach, yoga, quality of life, menopause 


\section{Introduction}

Menopause is the stage when the menstrual period permanently stops, and is a part of every woman's life. This stage usually occurs between the ages of 40 and 60 years, and is associated with hormonal, physical, and psychological changes. These changes can occur gradually or abruptly. It can start as early as the age of 30 years or not until as late as 60 years. It can also occur when the ovaries are removed or have stopped functioning. Symptoms include irregular menstruation, changes in sexual desire, hot flashes, vaginal dryness and urinary problems, changes in appearance, mood changes, sleep disturbances, palpitations, and backache. Estrogen and progesterone levels play the biggest part in menopause. In this stage, the ovaries make less estrogen and progesterone. When the body produces less of these hormones, the parts of the body that depend on estrogen to keep them healthy will react, and this often causes discomfort for women. ${ }^{1,2}$

The 2008 consensus statement by the Indian Menopause Society showed that the average age of menopause in India is 47.5 years, which is lower than the average age of 51 years for North American and European women. Premature menopause is on the rise in India due to a combination of environmental and genetic factors. Observational studies suggest that as many as $75 \%$ of women experience hot flashes after menopause. Left untreated, most women will have spontaneous cessation of hot flashes within 5 years, although some women continue to experience distressing symptoms for 30 years or more. Indian women living in rural and urban areas report urogenital symptoms, including urinary frequency, urgency, incontinence and dryness, and general body aches and pains. Women in urban areas complain more about having hot flashes, mood swings, psychological problems, and sexual problems. The onset of menopause heralds a time of diminished estrogen exposure, which may have both acute and chronic effects on health and quality of life.,

Menopause does not really require medical treatment since it is a natural biological process. Treatments for menopause focus on relieving its symptoms and preventing any chronic condition that may occur during the postmenopausal years, such as heart disease and osteoporosis. Exercise, an appropriate diet, not smoking, and reduction of stress are also effective ways to make menopause more bearable and also facilitate in preventing the chronic ailments that can occur in the postmenopausal years. ${ }^{1}$

Menopause is a stressful time for some women. However, strategies for managing stress can help women cope not only with menopause, but with life and aging in general.
Practices such as relaxation exercises, biofeedback, aerobic exercise, yoga, meditation, and breathing techniques are tools that enable these women to deal with stress in their lives. ${ }^{5}$

Quality of life (QoL) has been defined by the World Health Organization (WHO) as the "individual's perceptions of their position in life in the context of the cultural and value systems in which they live and in relation to their goals, expectations, standards and concerns". It is a broadranging concept incorporating in a complex way a person's physical health, psychological state, level of independence, social relationships, and personal beliefs, as well as their relationships to salient features of the environment. QoL is the main goal of health care, is a significant factor for individual health, and is used to plan and evaluate health care programs. ${ }^{6,7}$

Conde et al found that the most prevalent symptoms of menopause were nervousness (67\%), and hot flushes and sweating (51\%). Factors associated with poorer QoL were sweating, palpitations, nervousness, dizziness, depression, insomnia, and dyspareunia. The authors observed that menopausal symptoms negatively affected QoL in postmenopausal women. ${ }^{8}$ Another study reported by McGinnis et al investigated factors influencing QoL during the transition to menopause. Participants reported experiencing the common symptoms of menopause, and stressed the variety of strategies used (such as strength training, walking, or yoga) to promote overall well-being. ${ }^{9}$ Lunny and Fraser investigated the use of complementary and alternative therapies in 423 menopausal women. Ninety-one percent of women reported trying such therapies, including vitamins $(61.5 \%)$, relaxation techniques (57.0\%), yoga/meditation (37.6\%), soy products (37.4\%), and prayer (35.7\%) for their symptoms. The most beneficial complementary and alternative therapies were reported to be prayer/spiritual healing, relaxation techniques, counseling/therapy, and therapeutic touch/Reiki. ${ }^{10}$

Yoga is an ancient holistic art of living that includes physical, mental, moral, and spiritual dimensions. Yoga has been studied as a method to help people cope with a number of health conditions, including menopause. ${ }^{11,12}$ Yoga exercises have a physiological effect by relaxing and gently stretching every muscle in the body, thereby improving blood circulation and oxygenation to all cells and tissues. This helps optimize the function of the endocrine glands and female reproductive system. ${ }^{13-15}$

Motivation for health promotion in menopausal women may be further strengthened if women perceive lifestyle modifications, especially exercise and yoga, as an alternative 
nonpharmacological way of managing menopausal symptoms, and increasing QoL is urgently needed. ${ }^{16}$

The present study evaluated the impact of a complementary health approach to improve QoL in menopausal women from selected villages in Chennai, India.

\section{Materials and methods}

A community-based interventional study was conducted in selected areas in Kattankulathur Block, which is a revenue area in the Kanchipuram District of Tamil Nadu, India. It has a total of 39 panchayat villages with a population of 197,596 inhabitants. After the initial survey conducted by the investigators, it was decided to include ten villages in the study. Based on the survey report, there were 12,043 menopausal women residing in the villages who were potentially eligible for the study. A simple random sampling technique ${ }^{17,18}$ was used to select menopausal women for the study. In the first stage, ten villages were selected using the lottery method. During the second stage of sampling, a list of addresses for all women aged 45-55 years was obtained from the primary health center. In the third stage, women who fulfilled the inclusion criteria were selected randomly by the lottery method from this list. Approximately 15-20 menopausal women from each village participated in the study. A schematic representation of the sampling technique is shown in Figure 1.

The sample size was calculated based on the results of a pilot study and was also computed by power analysis. The sample size was also estimated by power analysis prior to the commencement of the study. The estimated sample size was 111 in each group. Considering an attrition rate of $10 \%$, the sample size was rounded to 130 in each group. The total sample for the study comprised 260 menopausal women. Of these, 130 were allocated to a study group and 130 to a control group.

The inclusion criteria for sample selection were: permanent cessation of menstruation naturally; age 45-55 years; bothersome menopausal symptoms; and women who practiced yoga for a minimum of 5 days per week. Exclusion criteria included gynecological problems (such as uterine fibroids, dysfunctional uterine bleeding, or prolapsed uterus), hormone replacement therapy, and existing medical treatment for symptomatic relief of menopause.

Baseline demographic and QoL data were collected from all study participants after selection of the sample. After the pretest, the menopausal women in the study group were taught about menopause and yoga. Yoga was demonstrated to the study group by the investigator. The yoga session was conducted in a public hall. All necessary physical arrangements, including a well-ventilated room, a noise-free, dust-free, and smoke-free environment, and provision of a mat for yoga practice were made for the women to practice yoga without any inconvenience. QoL was assessed by the investigator using the same questionnaire at weeks 6,12 , and 18 , and reinforcement sessions were implemented following each test. The investigator remained with the women while they completed the questionnaire and answered any questions.

\section{Ethical considerations}

Formal approval was obtained from SRM University review board and SRM University ethics committee. Both written

Kattankulathur Block (covers 39 villages)

Selection of ten villages (first randomization, lottery method)

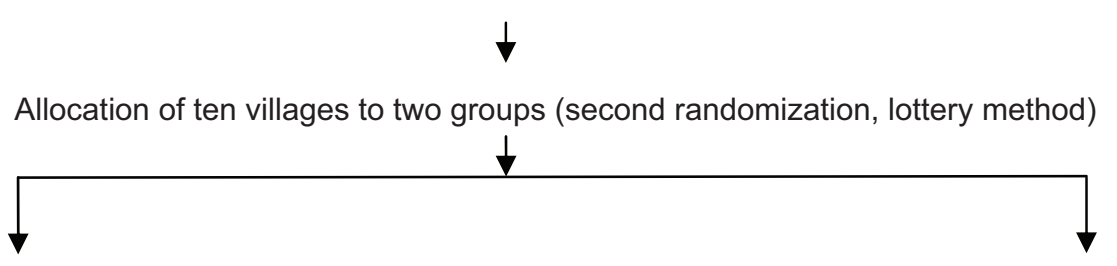

Five villages comprising study group

Five villages comprising control group

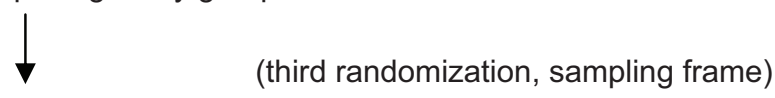

Selection of menopausal women $(n=130)$

Selection of menopausal women $(n=130)$

Figure I Schematic representation of sampling technique. 
and verbal information about the study were given in the local language to all women who participated in the study. Women were asked to participate voluntarily. The study objectives, benefits, problems, and time period involved in practicing yoga were explained in the consent form. Women who agreed to participate had the right to withdraw at any time during the study.

\section{Data collection}

The questionnaire used in this study comprised two sections. Section 1 pertained to information regarding demographic data, including age, religion, marital status, type of family, availability of a support system, age of menarche, parity, and duration of attainment of menopause. Section 2 consisted of the standardized WHO QoL-BREF scale ${ }^{19}$ to assess QoL in menopausal women. The Tamil version of the WHO QoL-BREF scale was used without any modification. Formal permission was obtained from the WHO to use this scale in the present study. The scale contains 26 items under four domains, ie, a physical domain, a psychological domain, a social domain, and an environment domain. Of the 26 items, 23 are positively scored and three (items 3, 4 and 26) are negatively scored on the scale. The first two items are examined separately: item 1 asks about the subject's overall perception of QoL and item 2 asks about the subject's overall perception of health in menopausal women (satisfaction of health status). The other 24 items are included in the domains. Raw scores are transformed into 100. Domain scores are scaled in a positive direction (higher scores denoting better QoL). The mean score for items within each domain is used to calculate the domain score. Mean scores are then multiplied by 4 in order to derive the domain scores and subsequently transformed to a 0-100 scale using the formula given by the WHO. Domain-wise interpretation of the data was done using various statistical methods.

\section{Description of yoga intervention}

The study group underwent a yoga training program under the supervision of the investigator. The yoga program comprised the following:

- Yogasanas (Tadasana, ardha kati chakrasana, Badrasana, Paschimothasana, Bhujangasana, Ardha Salabhasana, Ardhahalasana, and Shavasana), five times for 25-30 minutes.

- Pranayama breathing exercises (Nadhisodhana Pranayama and Sitali Pranayama), repeated 8-10 times for 5-10 minutes.

- Meditation, whereby women were asked to chant "Om" during meditation for 5-10 minutes. This is believed to contain cosmic energy that helps to relieve a person's individual suffering and helps to enhance memory function, improve interpersonal relationships, and allow more restful sleep, as well as enabling significant stress reduction.

Initially, intensive training on the steps of yoga was provided in the study group for 1.5 hours per day on 5 consecutive days. After 5 days of intensive yoga training, the women practiced yoga at home on their own for 35-40 minutes a day, and practiced group yoga for 2 days a week under the supervision of the investigator for 18 weeks. The investigator distributed an instruction manual on the steps of selected yoga practice for the women's self-reference at home after 5 days of continuous yoga practice. A yoga practice diary was used to confirm regular yoga practice at home. The women in the control group did not participate in the yoga program; however, on completion of the study, they also underwent intensive yoga training for 5 days.

\section{Statistical analysis}

Statistical Package for the Social Sciences version 16 software (SPSS Inc., Chicago, IL, USA) and Instat were used for the data analysis. The Student's independent $t$-test was used to compare values between the study and control groups. The chi-square test was used for comparison and association between the variables. One-way analysis of variance was used for comparison of variables. A $P$-value less than 0.05 was considered to be statistically significant.

\section{Results}

Of the initial 260 participants, two in the study group and four in the control group withdrew because of a change in residence, family events (marriage and religious festivals), or illness. The data analysis was performed for the remaining 254 participants (128 in the study group and 126 in the control group).

The baseline values were not significantly different between the study and control groups for any of the demographic variables, including age $(P=0.94)$, religion $(P=0.74)$, marital status $(P=0.91)$, type of family $(P=0.67)$, availability of a support system $(P=0.52)$, age of menarche $(P=0.40)$, parity $(P=0.47)$, and duration of menopause $(P=0.96)$, (Table 1).

The baseline values for item 1 on the QoL scale showed that $56(44 \%)$ menopausal women in the study group and $62(49 \%)$ in the control group had very poor QoL, and only five $(4 \%)$ in the study group and seven $(6 \%)$ in the control group had good QoL before the intervention. The results showed no statistically significant difference in baseline 
Table I Demographic variables of menopausal women $(n=254)$

\begin{tabular}{|c|c|c|c|c|c|}
\hline \multirow[t]{2}{*}{ Demographic variables } & \multicolumn{2}{|c|}{ Study group $(n=\mid 28)$} & \multicolumn{2}{|c|}{ Control group $(n=\mid 26)$} & \multirow[t]{2}{*}{$P$-value } \\
\hline & $\mathbf{n}$ & $\%$ & $\mathbf{n}$ & $\%$ & \\
\hline Age, years (mean $\pm S D$ ) & \multicolumn{2}{|l|}{$49.42 \pm 2.71$} & \multicolumn{2}{|l|}{$49.4 I \pm 2.70$} & $\begin{array}{l}\chi^{2}=0.38 \\
P=0.94\end{array}$ \\
\hline \multicolumn{6}{|l|}{ Religion } \\
\hline Hindu & 87 & 68 & 80 & 63.5 & $\chi^{2}=0.59$ \\
\hline Muslim & 18 & 14 & 21 & 16.7 & $P=0.74$ \\
\hline Christian & 23 & 18 & 25 & 19.8 & \\
\hline \multicolumn{6}{|l|}{ Marital status } \\
\hline Married & 91 & 71.1 & 88 & 69.8 & $\chi^{2}=0.55$ \\
\hline Separated & 13 & 10.1 & 13 & 10.3 & $P=0.91$ \\
\hline Widow & 12 & 9.4 & 15 & 11.9 & \\
\hline Single & 12 & 9.4 & 10 & 8 & \\
\hline \multicolumn{6}{|l|}{ Type of family } \\
\hline Joint family & 43 & 33.6 & 36 & 28.6 & $\chi^{2}=0.79$ \\
\hline Nuclear family & 80 & 62.5 & 84 & 66.7 & $P=0.67$ \\
\hline Extended family & 5 & 3.9 & 6 & 4.8 & \\
\hline \multicolumn{6}{|l|}{ Availability of support system } \\
\hline Self group & 36 & 28.1 & 29 & 23.0 & $\chi^{2}=2.27$ \\
\hline Friends & 29 & 22.6 & 24 & 19.0 & $P=0.52$ \\
\hline Relatives & 55 & 43.0 & 66 & 52.4 & \\
\hline Others & 8 & 6.3 & 7 & 5.6 & \\
\hline \multirow[t]{2}{*}{ Age of menarche, years (mean $\pm S D$ ) } & \multirow{2}{*}{\multicolumn{2}{|c|}{$13.19 \pm 1.95$}} & \multirow{2}{*}{\multicolumn{2}{|c|}{$|3.37 \pm 2.0|$}} & $\chi^{2}=1.83$ \\
\hline & & & & & $P=0.40$ \\
\hline \multicolumn{6}{|l|}{ Parity } \\
\hline Nulliparous & 5 & 3.9 & 4 & 3.2 & $\chi^{2}=2.71$ \\
\hline Primiparous & 54 & 42.2 & 64 & 50.8 & $P=0.47$ \\
\hline Multiparous & 62 & 48.4 & 49 & 38.9 & \\
\hline Grand multiparous & 7 & 5.5 & 9 & 7.1 & \\
\hline \multicolumn{6}{|c|}{ Duration of attainment of menopause, years } \\
\hline $\mathrm{I}-2$ & 63 & 49.2 & 63 & 50.0 & $\chi^{2}=0.31$ \\
\hline$>2-3$ & 40 & 31.2 & 40 & 31.7 & $P=0.96$ \\
\hline$>3-4$ & 18 & 14.1 & 18 & 14.3 & \\
\hline$>4-5$ & 7 & 5.5 & 5 & 4.0 & \\
\hline
\end{tabular}

Abbreviation: SD, standard deviation.

QoL values between the study group and the control group $\left(\chi^{2}=1.430, P=0.698\right)$.

In the study group, the majority of the women, ie, 45 $(35 \%)$ on post-test $1,56(44 \%)$ on post-test 2 , and $68(53 \%)$ on post-test 3, had good QoL after practicing yoga for 18 weeks. In the control group, most of the women, ie, 58 (46\%) on post-test 1,55 (44\%) on post-test 2, and $53(42 \%)$ on post-test 3 , had very poor QoL after 18 weeks. There was a highly statistically significant difference found on all the post-tests $(P=0.000)$ (Table 2$)$.

The baseline values for item 2 on the QoL scale indicated that the majority of the menopausal women in the study group (46\%) and in the control group (47\%) were very dissatisfied with their health before practicing yoga. There was no statistically significant difference in baseline QoL values between the study and control groups $\left(\chi^{2}=1.191\right.$, $P=0.755)$.
After the yoga intervention, 47 (37\%) women in the study group were satisfied with their health after 6 weeks, 54 (42\%) after 12 weeks, and 63 (49\%) after 18 weeks. In the control group, the majority of the menopausal women, ie, $55(44 \%)$ on post-test $1,54(43 \%)$ on post-test 2 , and $50(40 \%)$ on post-test 3 were dissatisfied with their health status. A highly statistically significant difference was found between all post-tests $(P=0.000)$ (Table 3$)$. Baseline values for domains of QoL were not significantly different between the study group and the control group. This was confirmed using the Student's independent $t$-test (Table 4). Table 5 shows a very highly statistically significant difference $(P=0.001)$ in the physical, psychological, and social domains of QoL, and a highly statistically significant difference $(P=0.01)$ in the environmental domain between the study and control groups after 6 weeks of yoga practice. There was an extremely highly statistically significant difference $(P=0.001)$ 
Table 2 Comparison of post-test level of quality of life in menopausal women $(n=254)$ in the study group versus the control group (quality of life, item I)

\begin{tabular}{|c|c|c|c|c|c|c|}
\hline \multirow[t]{2}{*}{ Post-test } & \multirow[t]{2}{*}{ Quality of life item I } & \multicolumn{2}{|c|}{ Study group } & \multicolumn{2}{|c|}{ Control group } & \multirow{2}{*}{$\begin{array}{l}\text { Chi-square } \\
\text { value }\end{array}$} \\
\hline & & $\mathbf{n}$ & $\%$ & n & $\%$ & \\
\hline \multirow[t]{5}{*}{ Post-test I } & Very poor & 16 & 13 & 58 & 46 & $\chi^{2}=48.573$ \\
\hline & Poor & 30 & 23 & 29 & 23 & $P=0.000 * *$ \\
\hline & Neither poor nor good & 37 & 29 & 30 & 24 & \\
\hline & Good & 45 & 35 & 9 & 7 & \\
\hline & Very good & - & - & - & - & \\
\hline \multirow[t]{5}{*}{ Post-test 2} & Very poor & - & - & 55 & 44 & $\chi^{2}=128.738$ \\
\hline & Poor & 11 & 9 & 32 & 25 & $P=0.000 * *$ \\
\hline & Neither poor nor good & 26 & 20 & 27 & 21 & \\
\hline & Good & 56 & 44 & 12 & 10 & \\
\hline & Very good & 35 & 27 & - & - & \\
\hline \multirow[t]{5}{*}{ Post-test 3} & Very poor & - & - & 53 & 42 & $\chi^{2}=171.996$ \\
\hline & Poor & - & - & 32 & 25 & $P=0.000$ *** \\
\hline & Neither poor nor good & 12 & 9 & 26 & 21 & \\
\hline & Good & 68 & 53 & 15 & 12 & \\
\hline & Very good & 48 & 38 & - & - & \\
\hline
\end{tabular}

Notes: **Highly significant at $P \leq 0.01$. - Indicates zero women.

in the physical, psychological, social, and environmental domains of QoL between the study and control groups after 12 and 18 weeks of yoga therapy.

On post-test 1, the mean gain score for women in the study group was 11.91 for the physical domain, 19.6 for the psychological domain, 14.4 for the social domain, and 10.3 for the environment domain ( $95 \%$ confidence intervals [CI] are shown in Table 5). After 12 weeks of yoga practice, the mean gain score was 20.6 in the physical domain, 28.8 in the psychological domain, 31.5 in the social domain, and 24.4 in the environment domain $(95 \% \mathrm{CI})$. After 18 weeks, the mean gain score was 30.06 in the physical domain, 34.37 in the psychological domain, 35.43 in the social domain, and 26.49 in the environment domain on post-test $3(95 \% \mathrm{CI})$. However, in the control group, not much difference was observed in mean gain score for any of the domains of QoL $(95 \% \mathrm{CI})$ when compared with the study group (see Table 5).

In the study group, younger menopausal women (aged 45-47 years) had a significant improvement in their physical domain $(F=3.02, P=0.03)$, psychological domain $(F=2.92$, $P=0.04)$, social domain $(F=2.89, P=0.04)$, and environment domain $(F=3.16, P=0.03)$ scores for QoL. Women who were married had a significant improvement in their physical domain $(F=4.89, P=0.01)$ and environment domain $(F=2.99$,

Table 3 Comparison of post-test level of overall perception of health (satisfaction of health status) in menopausal women ( $\mathrm{n}=254$ ) in the study group versus the control group (quality of life, item 2)

\begin{tabular}{|c|c|c|c|c|c|c|}
\hline \multirow[t]{2}{*}{ Post-test } & \multirow[t]{2}{*}{ Quality of life item 2} & \multicolumn{2}{|c|}{ Study group } & \multicolumn{2}{|c|}{ Control group } & \multirow{2}{*}{$\begin{array}{l}\text { Chi-square } \\
\text { value }\end{array}$} \\
\hline & & $\mathbf{n}$ & $\%$ & $\mathbf{n}$ & $\%$ & \\
\hline \multirow[t]{5}{*}{ Post-test I } & Very dissatisfied & 12 & 9 & 55 & 44 & $\chi^{2}=57.487$ \\
\hline & Dissatisfied & 36 & 28 & 35 & 28 & $P=0.000 * *$ \\
\hline & Neither satisfied nor dissatisfied & 33 & 26 & 29 & 23 & \\
\hline & Satisfied & 47 & 37 & 7 & 5 & \\
\hline & Very satisfied & - & - & - & - & \\
\hline \multirow[t]{5}{*}{ Post-test 2} & Very dissatisfied & - & - & 54 & 43 & $\chi^{2}=123.11$ \\
\hline & Dissatisfied & 13 & 10 & 30 & 24 & $P=0.000 * *$ \\
\hline & Neither satisfied nor dissatisfied & 29 & 23 & 32 & 25 & \\
\hline & Satisfied & 54 & 42 & 10 & 8 & \\
\hline & Very satisfied & 32 & 25 & - & - & \\
\hline \multirow[t]{5}{*}{ Post-test 3} & Very dissatisfied & - & - & 50 & 40 & $\chi^{2}=168.889$ \\
\hline & Dissatisfied & - & - & 28 & 22 & $P=0.000^{* *}$ \\
\hline & Neither satisfied nor dissatisfied & 15 & 12 & 35 & 28 & \\
\hline & Satisfied & 63 & 49 & 13 & 10 & \\
\hline & Very satisfied & 50 & 39 & - & - & \\
\hline
\end{tabular}

Notes: **Highly significant at $P \leq 0.01$. - Indicates zero women. 
Table 4 Comparison of baseline values of domain-wise quality of life between menopausal women ( $n=254)$ in the study group versus the control group

\begin{tabular}{|c|c|c|c|c|c|}
\hline \multirow[t]{2}{*}{ QoL domains } & \multicolumn{2}{|c|}{ Study group $(n=128)$} & \multicolumn{2}{|c|}{ Control group $(n=\mid 26)$} & \multirow{2}{*}{$\begin{array}{l}\text { Student's independent } \\
\text { t-test }\end{array}$} \\
\hline & Mean & SD ( \pm ) & Mean & SD ( $( \pm)$ & \\
\hline Physical & 40.84 & 7.71 & 41.12 & 16.27 & $t=0.17 ; P=0.86$ \\
\hline Psychological & 39.00 & 14.52 & 40.11 & 16.49 & $t=0.57 ; P=0.57$ \\
\hline Social & 39.04 & 18.26 & 39.89 & 21.66 & $t=0.02 ; P=0.73$ \\
\hline Environmental & 35.87 & 17.89 & 36.35 & 21.77 & $t=0.19 ; P=0.84$ \\
\hline
\end{tabular}

Note: Significant at $P \leq 0.05$.

Abbreviations: QoL, quality of life; SD, standard deviation.

$P=0.03)$ scores. Women who were menstruating regularly had a significant improvement in their physical domain $(t=2.09, P=0.03)$, psychological domain $(t=2.10, P=0.04)$, and social domain $(t=2.11, P=0.04)$ scores.

The results of the present study indicate that menopausal women who had attained menopause less than 1-2 years previously had a significant improvement in the social domain ( $F=2.88, P=0.04$ ) of QoL. Women who attained menarche at the age of 11-13 years showed a significant improvement in psychological domain $(F=3.85, P=0.02)$ and environment domain $(F=2.78, P=0.05)$ scores. No adverse events were reported by any of the women in the study group after yoga practice.

\section{Discussion}

With increased life expectancy, women now spend onethird of their lives in the postmenopausal years. Thus, more attention is needed for menopausal symptoms. QoL may be severely compromised in affected women. Estrogen replacement therapy is the most effective treatment, but has some limitations, and there remains a need to explore new options for the management of menopausal symptoms. Yoga has been utilized as a therapeutic tool to achieve positive health and to control and cure disease. There have been multiple studies which have combined the many aspects of yoga into a general yoga session in order to investigate its effects on menopausal symptoms and QoL. ${ }^{20}$

Nowadays, QoL is considered to be an important outcome that reflects the impact of health conditions, diseases, and treatments from the subjective perspective of the patient. Thus, evaluation of $\mathrm{QoL}$ is an important component for providing a more complete picture of the effects of menopause as well as evaluating the possible benefits of different treatments and therapies. Although still controversial, many authors have supported the association between menopause and poorer QoL. ${ }^{21}$

Shyu et al reported that the presence of menopausal symptoms increases the likelihood of poor health-related QoL and health care resource utilization. ${ }^{22}$ A study by Karaçam and Seker showed that there was a significant and moderately negative relationship between total menopausal symptom

Table 5 Comparison of post-test means and standard deviations of physical, psychological, social and environment domain scores for quality of life in menopausal women $(n=254)$ between study and control group at weeks 6,12 , and 18

\begin{tabular}{|c|c|c|c|c|c|c|c|c|}
\hline \multirow[t]{2}{*}{$\begin{array}{l}\text { Post- } \\
\text { test }\end{array}$} & \multirow[t]{2}{*}{ QoL domains } & \multicolumn{2}{|c|}{$\begin{array}{l}\text { Study group } \\
(\mathrm{n}=128)\end{array}$} & \multirow[t]{2}{*}{$\begin{array}{l}\text { Mean gain score } \\
\text { with } 95 \% \mathrm{Cl}\end{array}$} & \multicolumn{2}{|c|}{$\begin{array}{l}\text { Control group } \\
(n=126)\end{array}$} & \multirow[t]{2}{*}{$\begin{array}{l}\text { Mean gain score } \\
\text { with } 95 \% \mathrm{Cl}\end{array}$} & \multirow[t]{2}{*}{$\begin{array}{l}\text { Student's } \\
\text { independent } t \text {-test }\end{array}$} \\
\hline & & Mean & SD $( \pm)$ & & Mean & SD $( \pm)$ & & \\
\hline Post- & Physical & 52.75 & 7.86 & $11.91(9.9,13.8)$ & 41.27 & 16.19 & $0.15(-3.3,4.6)$ & $t=7.2 \mathrm{I} ; P=0.00 \mathrm{I} * * *$ \\
\hline \multirow[t]{3}{*}{ test I } & Psychological & 58.60 & 24.97 & $19.6(14.5,24.6)$ & 40.17 & 16.25 & $0.06(-4.0,4.1)$ & $t=6.96 ; P=0.00 I^{* * * *}$ \\
\hline & Social & 53.52 & 24.36 & | $4.4(9.2,19.8)$ & 40.34 & 22.31 & $0.45(-5.0,5.9)$ & $t=4.49 ; P=0.00 I^{* * *}$ \\
\hline & Environmental & 46.12 & 22.44 & $10.3(5.3,15.2)$ & 37.01 & 20.83 & $0.66(-3.3,4.5)$ & $t=3.35 ; P=0.0 I^{* *}$ \\
\hline Post- & Physical & 61.46 & 12.33 & $20.6(18.1,23.1)$ & 41.78 & 8.45 & $0.66(-3.4,4.5)$ & $t=|4.82 ; P=0.00| * * *$ \\
\hline \multirow[t]{3}{*}{ test 2} & Psychological & 67.75 & 19.28 & $28.8(24.5,32.9)$ & 41.20 & 15.83 & $1.09(-3.8,5.6)$ & $t=I|.99 ; P=0.00| * * *$ \\
\hline & Social & 70.57 & 21.56 & $31.5(26.6,36.4)$ & 41.00 & 21.03 & I.II $(-4.2,6.6)$ & $t=I \mathrm{I} .06 ; P=0.00 \mathrm{I} * * *$ \\
\hline & Environmental & 60.26 & 20.87 & $24.4(19.6,29.2)$ & 37.63 & 21.04 & $1.28(-4.0,6.9)$ & $t=8.6 \mathrm{I} ; P=0.00 \mathrm{I} * * *$ \\
\hline Post- & Physical & 70.90 & 13.80 & $30.06(27.4,32.7)$ & 42.80 & 9.02 & $1.68(-2.9,6.4)$ & $t=19.17 ; P=0.001 * * *$ \\
\hline \multirow[t]{3}{*}{ test 3} & Psychological & 73.37 & 18.56 & $34.37(31.6,37.1)$ & 41.45 & 15.32 & $1.34(-2.7,5.3)$ & $t=|4.93 ; P=0.00| * * *$ \\
\hline & Social & 74.54 & 20.10 & $35.43(32.2,38.7)$ & 41.77 & 20.50 & $1.88(-2.52,6.3)$ & $t=12.86 ; P=0.00 \mid * * *$ \\
\hline & Environmental & 62.36 & 19.27 & $26.49(23.6,29.4)$ & 37.93 & 21.89 & $1.58(-3.03,6.8)$ & $t=9.44 ; P=0.00 I^{* * *}$ \\
\hline
\end{tabular}

Notes: $* * P \leq 0.01 ; * * * P \leq 0.001$.

Abbreviations: $\mathrm{Cl}$, confidence interval; SD, standard deviation; QoL, quality of life. 
scores and QoL scores. A large number of factors were associated with experience of menopausal symptoms, and menopausal symptoms had negative effects on QoL. ${ }^{23}$

The results of our study show that QoL in menopausal women was significantly improved in the physical, psychological, social, and environmental domains by practicing yoga for 18 weeks in comparison with a control group. Our findings are consistent with those of a study by Reed et al who investigated the efficacy of three nonhormonal therapies for menopause-related QoL in women with vasomotor symptoms. In their study, perimenopausal and postmenopausal women aged 40-62 years were assigned randomly to yoga $(n=107)$, exercise $(n=106)$, or usual activity $(n=142)$, and also assigned randomly to a double-blind comparison of omega-3 $(n=177)$ and placebo $(n=178)$ capsules. For the yoga group only, baseline to 12-week improvements were seen in Menopause Quality of Life vasomotor symptom domain and sexuality domain scores. They found that yoga appears to improve QoL in healthy sedentary menopausal women. ${ }^{24}$

Likewise, in the current study, the mean gain score was high in all domains of QoL in the study group (95\% CI) at weeks 6,12 , and 18 . The overall mean gain score in the study group was 31.58 versus 1.61 in the control group. The overall mean gain score difference was 29.97 in all QoL domains between the study group and the control group. This shows that the intervention of yoga was effective in improving QoL for the women in the study group.

These study findings are consistent with those of a study of Iyengar yoga for symptoms of menopause by Mastrangelo et al. This study included six women aged 44-62 years who participated in a 70-minute Iyengar yoga class. The MenopausalSpecific Quality of Life survey was used to measure vasomotor, psychosocial, physical, and sexual functioning, and the Sit-andReach Test was used to assess hamstring flexibility. Eighty percent of participants demonstrated an increase in flexibility, and five participants reported a decrease in menopausal symptoms and better QoL following the 8-week program. ${ }^{25}$

Yoga has been used as a tool for physical, emotional, and spiritual health for thousands of years. For women at midlife and beyond, yoga offers a primary form of menopause medicine that can help them cope with a wide range of symptoms without negative side effects. The yoga practices that support good health as a woman's body moves through menopause also help her to make the most of her passage into the "wisdom" years. ${ }^{26}$

The main limitation of our study is that other healthy lifestyle practices, including exercise and walking, could have influenced the outcome of the study, and could not be controlled by the investigators.

\section{Conclusion}

The present study concluded that QoL could be greatly improved in menopausal women by 18 weeks of yoga practice. The practice of yoga as an approach to holistic health is a powerful tool for helping women experience the passage into menopause as a positive event, both physically and spiritually. Yoga is an enjoyable alternative exercise that increases QoL and reduces menopausal symptoms. Women who regularly practice yoga find that they are able to enjoy menopause and experience the freedom, liberation, and energy that it brings. This study suggests that yoga can be considered as a complementary therapy or an alternative method for improving QoL in menopausal women.

\section{Implications for practice}

- Health care professionals can use findings of evidencebased research to identify and provide resources for women to enhance QoL and promote overall health and well-being.

- Nurses in the community play a vital role in disseminating evidence-based complementary therapy to help menopausal women in alleviating their problems; evidencebased practice can facilitate quality improvement of women's health.

- Yoga can be preliminarily recommended as an additional intervention for women who suffer from physical and psychological complaints associated with menopause.

- Yoga is popular as a complementary and alternative therapy and can be added to the scientific evidence so that gynecologists can recommend it to their patients instead of prescribing hormone therapy.

\section{Acknowledgments}

The authors extend their sincere thanks to Dr Hema for yoga training and Dr Venkatesan, statistician, for his guidance on advanced statistical analysis. Heartfelt thanks to our family members and friends. All the women who volunteered to participate in this study are sincerely acknowledged.

\section{Disclosure}

The authors report no conflicts of interest in this work.

\section{References}

1. ABC of yoga.com.yoga for menopause. Cope with menopause through yoga. Available from: www.staryoga.com/yoga-for-menopause. Accessed February 8, 2014.

2. Ramamurthy I. Menopause. In: Sengupta B, Chattopadhyay SK, Verma TR, editors. Gynaecology for Post Graduates and Practitioners. New Delhi, India: Elsevier; 2007. 
3. Reid RL. Menopause. In: Bieber EJ, Sanfilippo JS, Horowitz IR, editors. Clinical Gynecology. Philadelphia, PA, USA: Churchill Livingstone, Elsevier; 2006.

4. Southin TE. Indian women and menopause. Indian Menopause Society; 2008. Available from: www.bellaonline.com/articles/art18499.asp. Accessed January 19, 2014.

5. About.com. Stress management in menopause. Available from: menopause.about.com/od/managing menopausal stress. Accessed March 6, 2014.

6. World Health Organization. QoL: measuring quality of life. Geneva, Switzerland: World Health Organization; 1996. Available from: www.who.int/mental_health/media/68.pdf. Accessed September 9, 2014.

7. Abedzadeh Kalarhoudi M, Taebi M, Sadat Z, Saberi F. Assessment of quality of life in menopausal periods: a population study in Kashan, Iran. Iran Red Crescent Med J. 2011;13:811-817.

8. Conde DM, Pinto-Neto AM, Santos-Sá D, Costa-Paiva L, Martinez EZ. Factors associated with quality of life in a cohort of postmenopausal women. Gynecol Endocrinol. 2006;22:441-446.

9. McGinnis PQ, Mastrangelo AM, Burke J, Rossi LD, Jones C, Siegrist N. Perception of quality of life during the menopause transition. Journal of Women's Health Physical Therapy. 2008;32(1):34.

10. Lunny CA, Fraser SN. The use of complementary and alternative medicines among a sample of Canadian menopausal-aged women. J Midwifery Womens Health. 2010;55:335-343.

11. Hema S. Yoga for Health. 1st ed. Tamil Nadu, India: Tara Yoga Publishing; 2003.

12. Nagarathna R, Nagendra HR. Yoga. 1st ed. Bangalore, India Vivekananda Yoga Research Foundation; 2008.

13. Lark SM. Integrative Medicine: Yoga For Menopause [webpage on the internet]. HealthWorld Online:2014. Available from: http://www. healthy.net/scr/article.aspx?ID=1370. Accessed December 10, 2013.

14. ABC of yoga [homepage on the Internet]. Yoga and Health. Maxlife Style International: 2012. Available from: www.abc-of-yoga.com/ health/. Accessed April 1, 2014.
15. Boyers L. Stress relief for menopause. Healthline - connect to better health. 2012. Available from: www.healthline.com/health/menopause/ stress-relief. Accessed January 4, 2014.

16. Luoto R. Hot flushes and quality of life during menopause. $B M C$ Women's Health. 2009;9:13.

17. Polit DF, Hungler BP. Nursing Research - Principles and Methods. 6th ed. Philadelphia, PA, USA: Lippincott; 1999.

18. Sharma SK. Nursing Research and Statistics. Philadelphia, PA, USA: Elsevier; 2011.

19. World Health Organization. QoL-BREF. Introduction, Administration, Scoring. Geneva, Switzerland: World Health Organization; 1996. Available from: www.who.int/mental_health/media/en/76.pdf. Accessed September 9, 2011.

20. Vaze N, Joshi S. Yoga and menopausal transition. Indian Menopause Society. J Midlife Health. 2010;1:56-58.

21. Moriyama CK, Oneda B, Bernardo FR, et al. A randomized, placebocontrolled trial of the effects of physical exercises and estrogen therapy on health-related quality of life in postmenopausal women. Menopause. 2008;15:613-618.

22. Shyu YK, Pan CH, Liu WM, Hsueh JY, Hsu CS, Tsai PS. Healthrelated quality of life and healthcare resource utilization in Taiwanese women with menopausal symptoms: a nation-wide survey. J Nurs Res. 2012;20:208-218.

23. Karaçam Z, Seker SE. Factors associated with menopausal symptoms and their relationship with the quality of life among Turkish women. Maturitas. 2007;58:75-82.

24. Reed SD, Guthrie KA, Newton KM, et al. Menopausal quality of life: RCT of yoga, exercise, and omega-3 supplements. Am J Obstet Gynecol. 2014;210:244.e1-e11.

25. Mastrangelo MA, Galantino ML, Chaloupka EC. Effects of yoga on quality of life and flexibility in perimenopausal and postmenopausal women. Med Sci Sports Exerc. 2005;37:s75.

26. Francina S. Yoga and the Wisdom of Menopause. A guide to physical, emotional and spiritual health at mid life and beyond. Deerfield Beach, FL, USA: Health Communications Inc; 2003.
Clinical Interventions in Aging

\section{Publish your work in this journal}

Clinical Interventions in Aging is an international, peer-reviewed journal focusing on evidence-based reports on the value or lack thereof of treatments intended to prevent or delay the onset of maladaptive correlates of aging in human beings. This journal is indexed on PubMed Central, MedLine,

\section{Dovepress}

CAS, Scopus and the Elsevier Bibliographic databases. The manuscript management system is completely online and includes a very quick and fair peer-review system, which is all easy to use. Visit http://www.dovepress. com/testimonials.php to read real quotes from published authors. 